\title{
Neurociência e o ensino da matemática: um estudo sobre os estilos de aprendizagem e as inteligências múltiplas
}

Neuroscience and the teaching of mathematics: a study on learning styles and multiple La neurociencia y la enseñanza de las matemáticas: un estudio de los estilos de aprendizaje y las inteligencias múltiples

Recebido: 07/09/2019 | Revisado: 16/09/2019 | Aceito: 12/10/2019 | Publicado: 15/10/2019

Francisco Geovane da Silva Araújo ORCID: https://orcid.org/0000-0002-7691-0217

Universidade Estadual Vale do Acaraú, Brasil

E-mail: franciscogeovanesilva@gmail.com

Daniel Brandão Menezes

ORCID: https://orcid.org/0000-0002-5930-7969

Universidade Estadual Vale do Acaraú, Brasil

E-mail: brandaomenezes@hotmail.com

Karoline de Sousa Bezerra

ORCID: https://orcid.org/0000-0002-8869-2245

Universidade Federal do Ceará, Brasil

E-mail: karolinesousab@hotmail.com

\section{Resumo}

O presente artigo evidencia uma análise sobre neurociência como condutor significativo na diretriz dos professores de matemática e no estudo da sua prática docente na qual se reflete o processo de ensino-aprendizagem. O objetivo da pesquisa é investigar a relação entre os Estilos de Aprendizagem e a Teoria das Múltiplas Inteligências no ensino da Matemática. Como metodologia de pesquisa para elucidar essas questões, foi adotada a pesquisa bibliográfica. A partir das análises do presente estudo, conclui-se que, a existência de uma relação inclusiva faz com que os estilos de aprendizagem e as inteligências múltiplas dos alunos se relacionem entre si. Contudo o estudo do cérebro para as aulas de matemática trará muitas vantagens para os professores, que facilitará o desempenho dos alunos.

Palavras-chave: Ensino de Matemática; Prática docente; Neuroeducação. 


\begin{abstract}
This article presents an analysis of neuroscience as a significant driver in the mathematics teachers' guideline and in the study of their teaching practice in which the teaching-learning process is reflected. The aim of the research is to investigate the relationship between Learning Styles and Multiple Intelligences Theory in mathematics teaching. As a research methodology to elucidate these questions, the bibliographic research was adopted. From the analysis of the present study, it is concluded that the existence of an inclusive relationship makes the learning styles and the multiple intelligences of the students relate to each other. However, brain study for math classes will bring many benefits to teachers, which will facilitate student performance.
\end{abstract}

Keywords: Mathematics teaching; Teaching practice; Neuroeducation.

\title{
Resumen
}

Este artículo destaca un análisis de la neurociencia como un impulsor significativo en la guía de los maestros de matemáticas y en el estudio de su práctica docente, que refleja el proceso de enseñanza-aprendizaje. El objetivo de esta investigación es investigar la relación entre los estilos de aprendizaje y la teoría de la inteligencia múltiple en la enseñanza de las matemáticas. Como metodología de investigación para dilucidar estas preguntas, se adoptó la investigación bibliográfica. Del análisis del presente estudio, se puede concluir que la existencia de una relación inclusiva hace que los estilos de aprendizaje y las inteligencias múltiples de los estudiantes se relacionen entre sí. Sin embargo, el estudio del cerebro para las clases de matemáticas traerá muchas ventajas para los maestros, lo que facilitará el rendimiento de los estudiantes.

Palabras clave: Enseñanza de las matemáticas; Práctica docente; Neuroeducación.

\section{Introdução}

O ensino da Matemática desde seu primeiro contato deve estabelecer um processo de construção do conhecimento de modo dinâmico e integrado, onde o professor tem como papel importante de promover a cognição matemática do aluno. Para que o professor consiga tornar este processo significativo, é necessário que o mesmo tenha tido uma preparação adequada durante sua formação e, além disso, precisa-se ter conhecimentos neurocientíficos, em relação as melhores ações no processo de ensino-aprendizagem, permitindo dessa forma, o 
desenvolver das habilidades lógicas cognitivas, e das competências de raciocínio perceptivo dos educandos.

Neste artigo mostra-se que ensinar Matemática é estender o conhecimento acerca de muitos fatores que o cérebro pode proporcionar ao ensino, ou seja, instigar o pensamento independente e coletivo, a criatividade e a habilidade de trabalhar com os diversos estilos de inteligência e aprendizagem. Alguns educadores matemáticos, necessitam buscar alternativas para aumentar a motivação para a aprendizagem, desenvolver o pensamento, a organização, a concentração e o conhecimento, dando estímulo à socialização e expandindo as interações do professor com os alunos.

Embora alguns pesquisadores tenham relacionado em suas concepções pedagógicas os saberes conforme a neurociência, apresentando conclusões que possibilitam afirmar que a neurociência cognitiva no campo educacional ainda não é uma realidade.

E por meio desse pensamento, o presente trabalho é justificado ao mostrar que a neurociência atualmente se torna uma ferramenta pedagógica matemática relevante para o aperfeiçoamento de habilidades e competências de raciocínio lógico matemático para o aluno, estudar os processos de como o cérebro aprende e desenvolve de acordo com cada aluno é importante para conseguir aperfeiçoar o ensino de Matemática. Ao identificar as diversas formas de aprendizagens dos alunos, é possível desenvolver uma comunicação mais eficiente, sendo capaz de dialogar diretamente com o mesmo, uma vez que o professor deve ter a percepção que para ensinar não basta dominar as diversas técnicas de ensino e conhecer todos os conteúdos de sua área, para isso é necessário que ele tenha o entendimento de três fundamentos, científico, pedagógico e experiencial, caso não faça esse assimilação, o professor será mais um mero transmissor de informações, sem qualquer tipo de relevância, correndo o risco de não acompanhar as mudanças educacionais propostas pela sociedade.

Analisar sobre diferentes pontos de vista é importante para conseguir benefício da necessidade de mostrar que o professor pode trabalhar de uma maneira alternada em sala de aula, as diversas ferramentas de ensino têm como centro, tornar o ensino da Matemática mais prazeroso, desenvolvendo do mesmo modo a motivação e o interesse. Introduzindo o incentivo nas estratégias de ensino, demonstrando por meio de uma percepção interacional, de que o estudo do cérebro para o meio educacional com ênfase no ensino da Matemática, compreende todos os níveis e especificidades de ensino, propondo, além disso, colaborar com a formação continuada do professor para o avanço do processo de ensino-aprendizagem, despertando dessa forma a curiosidade sobre o tema. 
Esse estudo é decorrência de uma pesquisa de revisão bibliográfica relacionados à neurociência e ensino de Matemática, que refletindo nesse contexto, a problemática deste trabalho norteia em suscitar discussões e indagações, por exemplo: Como utilizar o conhecimento sobre o cérebro para aumentar os índices de aprendizado em matemática? A aversão dos alunos por parte da matemática pode originar-se da dificuldade em interagir com o seu professor?

Diante do apresentado e a partir de analises bibliográficas, interessa-nos explicar: a importância de conhecer o funcionamento o cérebro do aluno bem como o uso dos estilos de aprendizagem relacionados com as múltiplas inteligências, nas quais permitem que o aluno faça da aprendizagem um artifício interessante e espairecido transformando a rotina da classe e despertando o interesse do aluno envolvido, buscando o objetivo de fazer com que os alunos gostem de aprender essa disciplina e que tenham um bom rendimento.

Para tal assunto o presente artigo tem como objetivo trabalhar essas estratégias de ensino-aprendizagem procedente da neuroeducação para o ensino de Matemática através dos processos de aprendizagem, ou seja, investigar a relação entre os estilos de aprendizagem e a Teoria das Múltiplas Inteligências no ensino da Matemática, onde alunos e professores são elementos de um mesmo conjunto na aquisição de conhecimentos, sendo íntegros de boas metodologias educacionais que impulsionam o indivíduo a sempre conhecer mais.

\section{Metodologia}

Como metodologia de pesquisa para elucidar essas questões foi adotada a pesquisa bibliográfica. Visto que, “[...] a pesquisa bibliográfica é desenvolvida com base em material já elaborado, constituído principalmente de livros e artigos científicos”. (GIL, 2002, p.44). Possibilitando uma ampla extensão de conhecimento a respeito sobre do estudo deste artigo, buscando esclarecer e entender o tema apresentado tornando a pesquisa significativa.

Para isso, é necessário fazer uma breve descrição de alguns conceitos importantes como, neurociência, neuroeducação e o comportamento do cérebro no aprendizado, quanto aos estilos de aprendizagem VAC (Visual, Auditivo e Cinestésico) e a TI (Teoria das Inteligências Múltiplas), familiarizando o leitor com os diferentes termos. Posteriormente, se estabelece a relação que possui essa ciência e o ensino de matemática.

\section{Conceitos importantes}


Através de suas teorias, Vygotsky e Gardner, provam que o indivíduo não atinge o conhecimento exclusivamente por meio de um único canal. Os estilos de aprendizagem diferem conforme o aluno, sendo da competência do educador ter a capacidade de perceber e analisar qual a forma mais satisfatória para este aluno, lembrando dessa forma o conceito de zona de desenvolvimento proximal (ZDP), onde diz que:

\begin{abstract}
“... a distância entre o nível de desenvolvimento real, que se costuma determinar através da solução independente de problemas, e o nível de desenvolvimento potencial, determinado através da solução de problemas sob a orientação de um adulto ou em colaboração com companheiros mais capazes." (Vygotsky, 1991, p.97).
\end{abstract}

A Teoria das Inteligências Múltiplas nos mostra inúmeras possibilidades para utilizarmos na prática o que Vygotsky relata em suas teorias, bem como conhecer o funcionamento do cérebro e a importância do professor de matemática em conhecer alguns conceitos neurocientíficos e quais suas contribuições para o ensino de Matemática.

\title{
3.1 Neurociência e Matemática
}

Uma das notáveis inquietudes que o professor de matemática tem como fundamento na sala de aula é como fazer o aluno aprender e, com ênfase nesse fundamento, a neurociência contribui no processo dessa competência. Dessa forma, Relvas constitui a Neurociência como: [...] um campo de estudo entre Anatomia, Biologia, Farmacologia, Fisiologia, Genética, Patologia, Neurologia, [...] e os vislumbrados estudos inerentes à educação humana no ensino e na aprendizagem. (2012, p. 34).

Sendo assim, a relação entre neurociência e educação é essencial para o ensino aprendizagem de matemática, uma vez que a aprendizagem ocorre por meio das redes cerebrais, onde há o tratamento de dados e informações, além dos elementos capazes de intervir acerca dessas situações. Nesse sentido,

A neurociência se constitui como a ciência de cérebro e a educação como a ciência do ensino e da aprendizagem e ambas têm uma relação de proximidade porque o cérebro tem uma significância no processo de aprendizagem da pessoa. Verdadeiro, seria, também afirmar o inverso: que a aprendizagem interessa diretamente o cérebro (OLIVEIRA, 2011, p. 22).

Simultaneamente busca-se boas alternativas de descobrir as dificuldades do cérebro e compreender a estrutura da memória e da inteligência e o que ocorre quando se aprende. E em relação a este pensamento Guerra explica que:

O cérebro é o órgão responsável pela aprendizagem. Durante a aprendizagem, educadores, professores e pais, por meio de suas práticas 
Res., Soc. Dev. 2019; 8(12):e198121670

ISSN 2525-3409 | DOI: http://dx.doi.org/10.33448/rsd-v8i12.1670

pedagógicas, fornecem estímulos que provocam transformações em circuitos neurais levando ao desenvolvimento e reorganização da estrutura cerebral, cuja função resulta em novos comportamentos e, portanto, em aprendizado (2010, p. 12).

Desse modo é de suma importância conhecer o funcionamento do cérebro, para assim compreender com mais cuidado diversos comportamentos do ser humano, incluindo o processo de aprendizagem. E a busca por conhecimentos neurocientíficos por parte do professor de matemática pode suceder em novas práticas que contribuam para uma aprendizagem realista. Pois

[...] o conhecimento, por parte do educador, do neurodesenvolvimento permite a utilização de teorias e práticas pedagógicas que levem em conta a base biológica e os mecanismos neurofuncionais, otimizando as capacidades do seu aluno" (OLIVEIRA, 2011, p.26).

Logo "educar requer criatividade, autonomia, paixão, motivação, dedicação, empatia, paciência, inovação, tempo, trabalho, energia. Saber como o cérebro funciona também pode ajudar" (GUERRA, 2010, p.09).

Atualmente, a neurociência está crescendo progressivamente na educação matemática, objetivando compreender o trabalho do cérebro humano referente ao pensamento matemático. Porém Cosenza e Guerra nos dizem que:

As neurociências não propõem uma nova pedagogia e nem prometem solução para as dificuldades da aprendizagem, mas ajudam a fundamentar a prática pedagógica que já se realiza com sucesso e orientam ideias para intervenções, demonstrando que estratégias de ensino que respeitam a forma como o cérebro funciona tendem a ser mais eficientes (2011, p.139).

Para Dos Santos e Souza (2016, p. 02), “A neurociência tem demonstrado o quão promissora pode ser uma parceria com a educação, trazendo todo o seu conjunto de saberes sobre o sistema nervoso central, local onde tudo acontece, desde os comportamentos, pensamentos, emoções e movimentos", ou seja, encarregando-se pela interação do indivíduo com o ambiente, então todos os estímulos sensoriais que um indivíduo recebe são processados pelo o cérebro e esse processamento vai dar uma resolução comportamental. E através desta parceria que surge a neurociência cognitiva, termo surgindo em uma corrida de taxi, e sendo uma das subdivisões da neurociência, que se dedica a estudar as competências mentais do indivíduo, como pensamento, aprendizagem, inteligência, memoria, linguagem e percepção, assim como o papel das emoções na construção do saber humano, trazendo grandes contribuições para a formação do educador. Também definida por Gazzaniga e Heatherton (2005, p.55): “A base desse campo é que o cérebro possibilita a mente e permite atividades cognitivas como o pensamento, à linguagem e a memória". Cita-se como uma das contribuições da neurociência para o ensino de matemática, a “contagem nos dedos" para o 
processo de aprendizagem de conceito numérico, ainda que haja uma convicção de que esse processo é um entrave à operação mental, a neurocognição propõe que trabalhar com os símbolos numéricos, requer o envolvimento de todo corpo, principalmente os dedos, sendo importantes para o crescimento das competências numéricas.

Nesse contexto, a neurociência nos mostra em suas pesquisas recentes a maneira como o cérebro aprende a Matemática deve estar inserida de forma alinhada com aula, buscando alicerce cientifico que fomente o aluno a ter prazer em trabalhar essa disciplina de forma simultânea em plena conexão com o seu cérebro, assim:

É importante que estimule os alunos a buscar explicações e finalidades para as coisas, discutindo questões relativas à utilidade da Matemática, como ela foi construída, como pode construir para a solução tanto de problemas do cotidiano como de problemas ligados à investigação científica. Desse modo, o aluno pode identificar os conhecimentos matemáticos como meios que o auxiliam a compreender e atuar no mundo (BRASIL, 1997, p. 62-63).

Refletindo-se o sobre esse assunto, na qual direciona o professor a refletir sobre o contexto construtivista do aluno em relação à matemática, onde o mesmo deve torna-se facilitador da aprendizagem e o aluno o núcleo no processo de ensino aprendizagem, ainda é possível notar a sua dificuldade de perceber a importância de estabelecer um contato proximal, não somente por suas técnicas ou metodologias de ensino, mas sim entender a maneira como o aluno recebe as informações e por não buscar o saber-cientifico, fica imprescindível o não desenvolvimento da matemática, uma vez que:

[...] o baixo desempenho dos alunos em Matemática é uma realidade em muitos países, não só no Brasil. Hoje o ensino de Matemática se resume em regras mecânicas oferecidas pela escola, que ninguém sabe onde utilizar. Falta formação aos docentes para aprofundar os aspectos mais relevantes, aqueles que possibilitam considerar os conhecimentos prévios dos alunos, as situações e os novos saberes a construir (SADOVSKY, 2007, p.15).

Além disso, Vygotsky afirma que:

O cérebro não é apenas o órgão que conserva e reproduz nossa experiência anterior, mas também o que combina e reelabora, de forma criadora, elementos da experiência anterior, erigindo novas situações e novo comportamento. (VIGOTSKI, 2009, p.14).

No momento em que se analisa os fatores importantes no processo de ensino, devemos levar em consideração o conhecimento do professor sobre a matemática, o experiencial, os recursos utilizados e como o cérebro do aluno funciona para que seja útil nesse processo de aprendizado, pois

[...] tem-se buscado, sem sucesso, uma aprendizagem em Matemática pelo caminho da reprodução de procedimentos e da acumulação de informações; nem mesmo a exploração de materiais didáticos tem contribuído para uma aprendizagem mais eficaz, por ser realizada em contextos pouco significativos e de forma muitas vezes artificial (BRASIL, 1997, p. 38). 
Para conter esta situação é necessário trabalhar o conhecimento cientifico do professor, bem como obter o conhecimento por meio das neurociências em parceria com a neuroeducação, principalmente sobre conhecer aluno e a importância de identificar o comportamento de entrada de conhecimento de cada um, e a relação em grupo.

Ressalta-se que apenas ponderamos de alguns princípios da Neurociência e que estudaremos agora as investigações relacionadas à forma como o cérebro aprende na neuroeducação, bem como os conceitos.

\subsection{Neuroeducação, Cérebro e Aprendizagem Matemática}

Direcionada à melhoria do ensino aprendizado a neuroeducação é o conjunto formado por subconjuntos sendo assim interdisciplinar que diz respeito à união da neurociência a psicologia e a educação, com propósito de criar melhores métodos de ensino. Segundo Hardiman e Denckla:

O novo campo da neuroeducação conecta neurocientistas que estudam aprendizagem e educadores que esperam fazer uso da pesquisa. Mas a construção de uma ponte entre esses grupos exigirá a superação de alguns obstáculos: um método precisa ser estabelecido para traduzir as descobertas da pesquisa em práticas educacionais $(2009$, p.01).

Nesta perspectiva, as pesquisas e iniciativas de neuroeducação têm compreendido um enorme desenvolvimento nos últimos anos, visto que professores, educadores e pesquisadores buscam compreender progressivamente como seus alunos aprendem e memorizam os conhecimentos ensinados, possibilitando alcançar descobertas sobre aprendizagem, memoria, linguagem e demais áreas da neurociência cognitiva, para instruir os educadores sobre as melhores estratégias de ensino.

Hardiman e Denckla (2009, p.1) tem a visão de que a educação deve ter através dos conhecimentos científicos novos modelos de ensino, e destacam a relevância da neurociência mostrando que "[...] a próxima geração de educadores deverá alargar a sua abordagem centrada não apenas no ensino da matemática, por exemplo, mas também na forma como o raciocínio matemático se desenvolve no cérebro". O aprendizado deve estar associado com a vida, pois abrange vários aspectos do indivíduo, e saber relacionar prática e teoria, pode posteriormente conduzi-lo ao conhecimento.

Quando surge o termo aprendizagem, tem-se sempre a concepção de que o desenvolvimento vem logo após o aprendizado, porém Vygotsky "parte do pressuposto da independência do processo de desenvolvimento e do processo de aprendizagem”. 


\section{Res., Soc. Dev. 2019; 8(12):e198121670 \\ ISSN 2525-3409 | DOI: http://dx.doi.org/10.33448/rsd-v8i12.1670}

(VYGOTSKY, 2010, p.103). Alicerçando a ideia de que o desenvolvimento ocorre antes do aprendizado, ainda nessa mesma perspectiva o autor diz que

[...] o aprendizado é considerado um processo puramente externo que não está envolvido ativamente no desenvolvimento. Ele simplesmente se utilizaria dos avanços do desenvolvimento ao invés de fornecer um impulso para modificar seu curso (VYGOTSKY, 2010, p. 103).

O processo de aprendizagem por sua vez relaciona-se fortemente com o estudo do cérebro uma vez que o aprendizado e o desenvolvimento, ainda segundo o autor supracitado diz que "o processo de desenvolvimento não coincide com o da aprendizagem, o processo de desenvolvimento segue o da aprendizagem, que cria a área de desenvolvimento potencial" (VYGOTSKY, 2010, P.116). Embora seja um novo paradigma, é nesse momento que se faz necessário compreender a neurociência e suas importâncias para a educação. Segundo Guerra:

A evolução nos garantiu um cérebro capaz de aprender, para garantir nosso bem-estar e sobrevivência e não para ter sucesso na escola. A menos que o bom desempenho escolar signifique esse bem-estar e sobrevivência do indivíduo. Na escola o aluno aprende o que é significativo e relevante para o contexto atual de sua vida. Se a "sobrevivência" é a nota, o cérebro do aprendiz selecionará estratégias que levem à obtenção da nota e não, necessariamente, à aquisição das novas competências (2011, p. 02).

Nessa perspectiva, compreender como o cérebro aprende é uma das formas de aproximação entre professor, aluno e conhecimento, visto que o mesmo tem a capacidade de processar, analisar e apresentar informações, tão rapidamente que impossibilita qualquer computador realizar esse processamento.

Segundo Silver (1994) o processo de aprendizagem pode divide-se em quatro fases: $1^{\circ}$ Registro da informação no cérebro (entrada - por meio dos sentidos); $2^{\circ}$ Organização e entendimento dessa informação (integração); $3^{\circ}$ Armazenamento (memória); $4^{\circ}$ A informação percorre o cérebro e é traduzida em ação no meio (saída-ato motor).

Logo é importante ter a percepção de que o cérebro pode realizar simultaneamente diversas funções, onde elas são imprescindíveis para o educador. Essas funções no ensino de Matemática são essenciais, pois a forma como cada uma é trabalhada, faz toda diferença no processo de aprendizagem.

Além disso, é apresentada a teoria do cérebro trino, referido por Maclean (1989), seu livro propaganda subliminar multimídia da seguinte maneira:

a) Cérebro réptil- eixo cerebral, hipotálamo, a sede primitiva dos componentes de autopreservação: alimentação, agressão e fuga, território e sexualidade;

b) Complexo límbico- cérebro mamífero, instintos de rebanho, cuidados com prole e hierarquias sociais; 
Res., Soc. Dev. 2019; 8(12):e198121670

ISSN 2525-3409 | DOI: http://dx.doi.org/10.33448/rsd-v8i12.1670

c) Neo-córtex- ultima camada, onde se processam a linguagem simbólica, as abstrações, calculo matemático, o cruzamento heurístico e arquivos (criatividade) (CALAZANS,2006, p.60).

E através desse estudo, tem-se a que cada uma dessas áreas tem influência no processo de ensino aprendizagem, por exemplo, emoções e fome dificultam aprendizagem. Vale ressaltar que o cérebro neo-córtex tem peso maior na aprendizagem matemática, pois está parte trabalha melhor com concentração e foco.

Outra parte do cérebro que também se relaciona com o desenvolvimento, à adaptação e aprendizagem é a Neuroplasticidade, definido por Guerra como "a propriedade de 'fazer e desfazer' conexões entre neurônios. Ela possibilita a reorganização da estrutura do Sistema Nervoso e do cérebro e constitui a base biológica da aprendizagem e do esquecimento" (2011, p. 06). Oliveira também explica que:

[...] entre o nascimento e a adolescência novos neurônios serão acrescentados ao cérebro, novos circuitos neuronais serão construídos em consequência da interação com o ambiente e da estimulação adequada. Este processo desacelera no adulto, mas não é interrompido; é parte do conceito de Neuroplasticidade (2011 p. 23-24).

Além do conceito de Neuroplasticidade, se tem que os sistemas que atuam em nossa mente, definidos por Kahneman (2012) como Sistema Rápido (Sistema 1) e o Sistema Devagar (Sistema 2), esses são imprescindíveis na aprendizagem matemática como, por exemplo, instigar o aluno a responder duas contas respectivamente, $5+5$ e $35 \times 12$, na primeira o mesmo responderá rapidamente sem muito esforço, já na segunda ele observar que é possível responder, porém necessitaram de recurso e de mais esforço. Nesse sentido o autor descreve:

O Sistema 1 como originando sem esforço as impressões e sensações que são as principais fontes das crenças explícitas e escolhas deliberadas do Sistema 2. As operações automáticas do Sistema 1 geram padrões de ideias surpreendentemente complexos, mas apenas o Sistema 2, mais lento, pode construir pensamentos em séries ordenadas de passos. Também descrevo circunstâncias em que o Sistema 2 assume o controle, dominando os irrefreáveis impulsos e associações do Sistema 1 (2012, p. 16).

Alicerçados a esses conceitos, os aspectos relacionados à aprendizagem matemática, como memória, emoção, atenção, motivação e plasticidade cerebral, são estudos que quando se estabelece uma conexão pode agir fortemente no desenvolvimento de competências e habilidades, principalmente acerca do conhecimento matemático.

Esses estudos se voltam principalmente para os processos educacionais relativos à aprendizagem, que por sua vez consiste em compreender como o cérebro aprende à Matemática, é nesse momento que a neuroeducação pode ajudar a relacionar os fatores que 
compõe esse processo de aprendizagem, tornando-se um veículo imprescindível na formação dos professores de matemática.

Atualmente os professores de matemática tentam buscar diversas formas de fazer com que o aluno goste ou simplesmente aprenda o básico sobre ela, porém acabam encontrando barreiras que os fazem desistir facilmente desse processo e assim a aprendizagem matemática regredindo cada vez mais ao longo do tempo, acarretando o déficit do mesmo quanto aos conteúdos matemáticos, logo é importante,

(...) oportunizar aos professores a compreensão de como o cérebro trabalha dá condições mais adequadas para que ele estimule a motivação em sala de aula e, de certa forma, assegura a possibilidade de sintonizar com os diversos tipos de alunos, os quais terão suas capacidades mais profundamente exploradas (CARVALHO, 2011, p. 545).

Alguns professores buscam métodos como jogo, slides, videoaulas, materiais manipuláveis, softwares, dentre outros, isso tudo para tentar criar uma proximidade do aluno com a matemática, que por sua vez alegam a dificuldade que os alunos sentem de aprender seja do modo tradicional, ou pelas diferentes formas de metodologias e recursos.

$\mathrm{Na}$ ausência de informações de como nosso cérebro faz o que faz, muitas vezes os professores atribuem o insucesso no aprender à incapacidade de os alunos realizarem determinados tipos de aprendizagem. Com isso, os professores se esquivam de sua responsabilidade como mediadores da construção do conhecimento (CAVALHO, 2011, p. 545).

Nessa perspectiva, o professor deve ir além desses artifícios para conseguir fazer essa proximidade, conhecer o aluno é substancial, bem como o emocional, o estilo de aprendizado, as inteligências múltiplas, para isso é necessário que haja transformações nas práticas de ensino, assim como aperfeiçoar os materiais já existentes para que todos os alunos se sintam familiarizados com a matemática, pois há décadas vivemos com o mesmo tradicionalismo no ensino de matemática.

Assim, o trabalho do educador pode ser mais significativo e eficiente quando ele conhece o funcionamento cerebral. Conhecer a organização e as funções do cérebro, os processos receptivos, os mecanismos da linguagem, da atenção e da memória, as relações entre cognição, emoção, motivação e desempenho, as dificuldades de aprendizagem e as intervenções a elas relacionadas contribui para o cotidiano do educador na escola (CONSEZA e GUERRA, 2011, p. 143).

Nesse pensamento, é necessário que o professor deva ter a concepção dos estilos de aprendizagem, já que, a neuroeducação pode estar inserida em métodos de aprendizados até mesmo, por exemplo, quando o aluno tem a necessidade de dissolver vários conteúdos das disciplinas curriculares na sua instituição de ensino, dentre elas a matemática que é o presente objeto de estudo e na qual é considerada por muitos alunos, como uma das mais difíceis de 
aprender, então desse modo encontra-se dificuldade de aprendizado, uma das questões que envolvem a neuroeducação são os estilos de aprendizagem.

\subsection{Estilos de aprendizagem: visuais, auditivos e cinestésicos}

Atualmente sabe-se das dificuldades que os professores de diversas disciplinas têm de ensinar seus alunos, mas daremos proeminência na disciplina de matemática, pois a mesma sempre foi e é descrita com uma das mais complexas de aprender e ensinar. Além dos obstáculos vistos pelo professor em criar estratégias de ensino nas quais haja uma relação edificante entre o aluno e a matemática, há também dificuldades por parte do aluno, que desde o primeiro momento quando se encontra com os números no início de sua vida estudantil, passam a ter uma percepção negativa dessa disciplina que é substancial sua aplicação para a vida, e é imprescindível que o primeiro contato da criança com a matemática não seja sincronicamente o último.

Diante as dificuldades que o professor de matemática se depara, torna-se a identificar qual representação os alunos utilizam é primordial para receber informações, e da mesma maneira gerar aprendizagem. Alguns autores abordam diferentes estilos de aprendizagem, mas daremos ênfase em três estilos: o visual, o auditivo e cinestésico, desenvolvida por Fernald e Keller e Orton- Gilingham, sendo definidos, respectivamente, como:

a) Estilo visual: neste grupo estão os estudantes que possuem habilidades de conhecer, interpretar e diferenciar os estímulos recebidos visualmente. A partir da visualização das imagens, é possível estabelecer relações entre ideias e abstrair conceitos.

b) Estilo Auditivo: estudantes com estilo auditivo possuem habilidades de conhecer, interpretar e diferenciar os estímulos recebidos pela palavra falada, sons e ruídos, organizando suas ideias, conceitos e abstrações a partir da linguagem falada.

c) Estilo Cinestésico: encontramos neste grupo estudantes que possuem habilidades de conhecer, interpretar e diferenciar os estímulos recebidos pelo movimento corporal (SALDANHA et al, 2016, p. 2).

Nesse contexto, Saldanha et al diz que os "Estilos de Aprendizagem, não é mais uma nova teoria de aprendizagem, mas estudos que demonstram que cada pessoa tem uma forma própria para ensinar e aprender" (2016. p.1). A influência desses estilos para o processo ensino-aprendizagem de matemática é necessário explorar o cognitivo do aluno, bem como sua recepção quanto aos conteúdos, pois os mesmo em uma turma podem diferir dos outros quanto aos estilos, e sua identificação é necessária para compreender suas dificuldades, e poder atuar de modo eficaz na aprendizagem, mas para isso "é de extrema importância que o professor conheça também seu próprio estilo de aprendizagem, pois estes influenciam 
sobremaneira no modo como o professor organiza sua aula, planeja estratégias diferenciadas, seleciona recursos materiais e se relaciona com os estudantes." (SALDANHA et al, 2016, p.5 apud CERQUEIRA, 2000), nessa perspectiva Saldanha et al, afirma que:

\begin{abstract}
Em geral, os professores costumam ensinar segundo seus próprios estilos de aprendizagem, desconsiderando as formas peculiares de aprendizagem de seus estudantes, conhecer-se e conhecer seus estudantes possibilitará a diversificação no seu modo de ensinar, esta ressignificação de sua prática pedagógica, considerando o estilo de aprendizagem de seus estudantes, resultará num processo de ensinagem mais significativo e aprendentes mais satisfeitos e mais ativos no seu processo de desenvolvimento (2016, p. 5).
\end{abstract}

O visual compreender melhor os conteúdos por escrito no caderno, por mais que o professor fale e explique, ás vezes é melhor transpor por escrito, principalmente a representação daquilo que se está explicando, ou seja, os alunos irão conhecer, compreender e interpretar os conteúdos desde que os mesmos sejam bem detalhados por escrito, na matemática esses alunos têm o costume de anotar as fórmulas, e mais facilidade de aprendizagem no estudo da geometria pois tendem a explorar mais o aspecto visual das coisas, por exemplo trabalhar frações nas formas geométricas com cores e harmonização torna-se mais claro o entendimento. Além disso, esses aprendizes podem dividir-se em verbais, com facilidade melhor na leitura e escrita e os não verbais, com dificuldade na escrita, porém aprendem com ilustrações e imagens. Deixando clara a importância das representações geométricas e espaciais para a aprendizagem matemática desses alunos.

Os auditivos não querem saber muito, por exemplo, se o professor vai mandar um email por escrito, às vezes ele prefere que o professor pegue o telefone e ligue para ele, converse e troque informações falando com esse aluno, ou seja, compreende e aprende através da linguagem falada, ou seja, em sala de aula preferem a comunicação oral, sendo interessantes as discussões e debates, pois o mesmo acaba tornando-se um bom ouvinte, fazendo com que exponha suas dúvidas, na matemática esses alunos necessitam da expressão oral do conteúdo para poder assimilar o que está sendo tratado, explicar o comportamento de um gráfico, ou uma resolução problema faz com ocorra a exploração desse estilo, os professores também podem apresentar conteúdos usando recursos auditivos.

Os alunos cinestésicos aprendem através do estimulo recebido pelo o corpo, ou seja, os mesmos preferem que o professor apresente matérias que possam ser tocados para se ter uma maior compreensão, pois o próprio tem uma mania de ficarem tocando, quando não se trabalha o corpo como o desejado os mesmos perdem concentração quanto à aprendizagem, eles gostam de pesquisas de campo e atividades em laboratórios, no contexto matemático temos vários artifícios para aproximação desses alunos com os conteúdos, bem como 
trabalhar conceitos através dos jogos e materiais manipuláveis, podendo intervi no processo de ensino aprendizagem da matemática.

Através desse contexto ressalta-se a importância de o professor distinguir entre os seus alunos quais são alunos visuais, auditivo ou cinestésico, e qual a importância dessas três representações para o ensino de matemática. Além disso, pode-se ter a percepção de que diferenciar essas três é imprescindível, mas saber unificá-las a fim de obtermos uma aula em que os três grupos de alunos se enquadrem e aprendam os conteúdos matemáticos de maneira simultânea é muito mais relevante. Saldanha et al diz que:

[...] o objetivo de conhecer e identificar os Estilos de Aprendizagem não deve servir para rotular, classificar ou dividir os estudantes, mas para ampliar suas possibilidades de uma aprendizagem significativa de maneira agradável, eliminando as possibilidades da apresentação de problemas de aprendizagem, isto é muito importante, pois os estudantes de que estamos tratando já são, devido a suas deficiências, discriminados pela sociedade (2016. p. 5).

Com isso torna-se evidente a importância na qual o professor em conhecer os alunos que se está trabalhando, esse conhecimento faz com que o professor possa reduzir os obstáculos inerentes encontrados em sala de aula e os motive a pesquisar e criar estratégias que possam intervir no processo de aprendizagem matemática. Além disso, temos a necessidade de identificar as várias formas de inteligências em sala de aula, pois como sabemos existes alunos que recebem conhecimentos por vários canais, porém a aplicação difere quanto ao tipo de inteligência, como por exemplo, alunos com o sistema de representação auditivo têm maiores habilidades em aprender ouvindo músicas, mas não necessariamente sua inteligência estará propícia a aprender a matemática ouvindo música, mas sim em usar a música para perceber a relação com matemática, para isso é necessário estudarmos sobre as inteligências múltiplas.

\subsection{Múltiplas Inteligências de Gardner e o ensino da matemática}

A inteligência geralmente é aceita por seu traço competitivo, isto é, uma concorrência onde apresentam vencedores e derrotados; se deve este entendimento ao pensamento de parte dos professores, na visão deles a inteligência é uma prática distinta das brincadeiras, não devemos conceber o seu uso somente como uma disputa. Despertar a inteligência do aluno nas aulas de matemática torna-se eficaz para a compreensão dos conteúdos. Segundo Espinosa os princípios da neuroeducação, nos diz que:

[...] estudantes aprendem melhor quando são altamente motivados do que quando não têm motivação; stress impacta aprendizado; ansiedade bloqueia 
Res., Soc. Dev. 2019; 8(12):e198121670

ISSN 2525-3409 | DOI: http://dx.doi.org/10.33448/rsd-v8i12.1670

oportunidades de aprendizado; estados depressivos podem impedir aprendizado; o tom de voz de outras pessoas é rapidamente julgado no cérebro como ameaçador ou não-ameaçador; as faces das pessoas são julgadas quase que instantaneamente (i.e., intenções boas ou más); feedback é importante para o aprendizado; emoções têm papel-chave no aprendizado; movimento pode potencializar o aprendizado; humor pode potencializar as oportunidades de aprendizado; nutrição impacta o aprendizado; sono impacta consolidação de memória; estilos de aprendizado (preferências cognitivas) são devidas à estrutura única do cérebro de cada indivíduo; diferenciação nas práticas de sala de aula são justificadas pelas diferentes inteligências dos alunos (ESPINOSA, 2008, p. 78).

Nesse contexto, o autor faz reflexões sobre a ideia e conceito de inteligência sempre que foram temas amplamente discutidos, tanto dentro quanto fora da academia, psicólogos, biólogos, filósofos, neurologistas procuram há muito tempo entender esse tema controverso. Ao logo do tempo foram desenvolvidos muitos testes e teorias sobre o que é, e como medir as inteligências, isso para o educador saber como os alunos aprendem e porque alguns têm uma facilidade maior de aprendizagem em relação aos demais. Insatisfeito com algumas formas de medir a inteligência de cada indivíduo, Howard Gardner, foi um psicólogo que "estudou o desenvolvimento e as habilidades simbólicas em crianças normais e talentosas e a diminuição destas habilidades em adultos com dano cerebral" (Gardner, 2002, p.19). No final do século XX desenvolveu a Teoria das Inteligências Múltiplas.

Segundo Gardner (1995, p.21) “a inteligência implica na capacidade de resolver problemas ou elaborar produtos que são importantes num determinado ambiente ou comunidade cultural. " Essa capacidade é vista como uma estratégia que produz um determinado sentido prático que causa significado ao conhecimento, fazendo com que o indivíduo aplique seus conhecimentos já adquiridos, desenvolvendo a capacidade de captar as informações em sua volta, claro que existe vários fatores influenciando, como nível de treinamento, comprometimento, oportunidade, dentre outros. Segundo Gardner:

A teoria das inteligências múltiplas, por outro lado, pluraliza o conceito tradicional. Uma inteligência implica na capacidade de resolver problemas ou elaborar produtos que são importantes num determinado ambiente ou comunidade cultural. A capacidade de resolver problemas permite à pessoa abordar uma situação em que um objetivo deve ser atingido e localizar a rota adequada para esse objetivo. A criação de um produto cultural é crucial nessa função, na medida em que captura e transmite o conhecimento ou expressa as opiniões ou os sentimentos da pessoa. Os problemas a serem resolvidos variam desde teorias científicas até composições musicais para campanhas políticas de sucesso $(1995$, p.21).

Embasada em habilidades especificas nas quais podem ter vários graus de eficiência. Gardner (1995) tendo definido que o importante é a diversidade do intelecto desenvolveu oito inteligências: inteligência linguística, inteligência lógico-matemática, inteligência espacial, 
inteligência musical, inteligência cinestésica/corporal, inteligência interpessoal, inteligência intrapessoal e inteligência naturalista.

Segundo a Teoria das Inteligências Múltiplas, o conjunto de capacidades dos seres humanos agrupa-se em oito inteligências amplas, definidas conforme Armstrong:

a) Inteligência linguística: a capacidade de usar as palavras de forma efetiva, quer oralmente, quer escrevendo.

b) Inteligência interpessoal: a capacidade de perceber e fazer distinções no humor, intenções, motivações e sentimentos de outras pessoas.

c) Inteligência intrapessoal: o autoconhecimento e a capacidade de agir adaptativamente com base neste conhecimento.

d) Inteligência lógico-matemática: a capacidade de usar os números de forma efetiva e de racionar bem.

e) Inteligência musical: a capacidade de perceber (por exemplo, como aficionado por música), discriminar (como um crítico de música), transforma (como compositor) e expressar (como musicista) formas musicais. Esta inteligência inclui sensibilidade ao ritmo, tom ou melodia e timbre de uma peça musical. Podemos ter um entendimento figural ou geral da música (global, intuitivo), um entendimento formal ou detalhado (analítico, técnico), ou ambos.

f) Inteligência espacial: a capacidade de perceber com precisão o mundo visuo-espacial (por exemplo, como caçador, escoteiro ou guia) e de realizar transformações sobre essas percepções (por exemplo, como decorador de interiores, arquiteto, artista ou inventor). Esta inteligência envolve sensibilidade à cor, linha, forma, configuração e espaço. Inclui também, a capacidade de visualizar, de representar graficamente ideias visuais e de orientar-se apropriadamente em uma matriz espacial.

g) Inteligência corporal-cinestésica: perícia no uso do corpo todo para expressar ideias e sentimentos (por exemplo, como ator, mímico, atleta ou dançarino) e facilidade no uso das mãos para produzir ou transformar coisas (por exemplo, como artesão, escultor, mecânico ou cirurgião). Esta inteligência inclui habilidades físicas específicas, tais como coordenação, equilíbrio, destreza, força, flexibilidade e velocidade, assim como capacidades proprioceptivas, táteis e hápticas.

h) Inteligência naturalista: perícia no reconhecimento e classificação das inúmeras espécies - a flora e a fauna - do meio ambiente do indivíduo, sensibilidade a outros fenômenos naturais (por exemplo, formação de nuvens e montanhas) e capacidade de distinguir entre seres "vivos" e "inanimados" (2001, p. 14-15).

Com base nessas definições, a Teoria das Inteligências Múltiplas pode exercer um papel enormemente considerável para o processo de ensino-aprendizagem, uma vez que a metodologia de ensino do professor deve beneficiar as características pessoais dos alunos diante ao conteúdo definido.

Dessa forma é importante a utilização da teoria das inteligências múltiplas nas aulas de matemática, embora os professores da área sempre tentem desenvolver o raciocínio lógico em seus alunos, é notório que eles deixam um enorme espaço a ser preenchido com atividades que despertem sua inteligência.

As inteligências múltiplas vêm mostrar como pode ser ensinada a Matemática em várias áreas do conhecimento, pois todos têm uma inteligência especifica, poderíamos usar 
isso como aliado no ensino da Matemática, por exemplo, aquele aluno que gosta de música talvez ceda em aprender uma parte da matemática que use música.

Algumas inteligências já são desenvolvidas diretamente no ensino da Matemática, como a lógico-matemática e a espacial, porém é necessária uma ação direcionada para trabalhar todas elas, é evidente que não será toda de uma vez, porém ao decorrer do ano letivo, o professor aos poucos pode direcionar a prática de estimular as inteligências individuais ou até mesma conjunta dos alunos, onde simultaneamente serão interligadas.

Dessa forma o professor de matemática pode realizar atividades na qual propícia o próprio a aluno descobrir em qual tipo ele se adequa melhor, sempre relacionando-as com a matemática, como na inteligência linguística (ao se expressar formas algébricas de maneira oral, escrita, leitura dos números e fórmulas), a interpessoal (capacidade de compreender a situação-problema, o desenvolvimento dos cálculos), a intrapessoal (o processo de construção do cálculo no coletivo, a aceitação de sugestões), a musical ( despertar o pensamento analítico, formal e detalhado), a corporal-cinestésica (o trabalho com materiais manipuláveis, os sólidos geométricos, dentre outros), a naturalista ( capacidade de observação nas aulas bem como a capacidade de distinguir elementos, relacionado a matemática concreta e abstrata).

Analisou-se posteriormente a relação dessas inteligências com os estilos de aprendizagem, explicando aplicação no ensino da Matemática. Esta aproximação, mostrou-se ao longo desse estudo como forma de aproximar os conteúdos matemáticos aos alunos, buscando inter-relacionar o seu estilo, inteligência e o estudo da disciplina de matemática, bem como as maneiras do professor realizar atividades que estimulem essa prática.

\section{Relação entre os estilos de aprendizagens e a teoria das inteligências múltiplas no ensino da matemática.}

A evolução da aprendizagem matemática se desenvolve com pouca intensidade, necessitando de aparatos que apoiem seu crescimento, entendendo-se que o aluno necessita de paciência interagir. $\mathrm{O}$ ensinamento se torna muitas vezes meras reiterações de atividades educacionais, tornando o estudo fatigante e causando um decrescimento na aprendizagem, buscando-se a resolução e aplicação de atividades para aguçar os canais de aprendizagem do aluno, e bem como o gosto de forma contagiante pela aprendizagem.

\subsection{Inteligência Linguística}


$\mathrm{Na}$ inteligência linguística, podemos perceber através desse estudo, que envolve os alunos auditivo, visuais e cinestésico, e para estimulá-los o professor pode aderir ao uso histórias em quadrinhos para demonstrar os conteúdos matemáticos, da mesma forma realizar debates através de apresentações, seria interessante os alunos criarem um dicionário de linguagem matemática com palavras e definições, estimular a audição dos alunos com explicações gravadas em áudio e para os visuais a escrita com o uso das tecnologias de resumos explicativos de fórmulas e fazer a transferência entre os colegas para relacionar o entendimento delas, bem como uma sequência de movimentos para a explicação do conteúdo abordado.

Dessa forma tornar a atividade interessante aos estudantes tentando ser o mais preciso possível em suas explicações é interessante que a mesma seja exposta para todos na lousa e cada um a tenha o material em suas mãos para maior agilidade e facilidade no acompanhamento ao professor, a leitura e interpretação nessa fase é de fundamental importância.

\subsection{Inteligência Lógico-Matemático}

Na inteligência lógico-matemático, o professor pode usar a criatividade para elaborar situações-problemas descritas, onde pode-se trabalhar com os alunos auditivos e visuais, uma vez que a matemática se relaciona com fatos reais, reduzindo o tradicionalismo motivando os alunos a perceberem a matemática como ferramenta importante, este trabalho torna-se significativo, e segundo Freire:

\footnotetext{
Há uma quase enfermidade da narração. A tônica da educação é preponderantemente esta - narrar, sempre narrar. Falar da realidade como algo parado, estático, compartimentado e bem-comportado. [...] Nela, o educador aparece como seu indiscutível agente, como o seu real sujeito, cuja tarefa indeclinável é "encher" os educandos dos conteúdos de sua narração. Conteúdos que são retalhos da realidade desconectados da totalidade em que se engendram e em cuja visão ganhariam significação (2005, p.65-66).
}

Neste pensamento o autor ressalta que o professor planeje e conduza uma prática sobre conteúdos que motive os alunos a raciocinar, para isso a matemática dispõe de várias situações em que se torna necessário o seu uso, estimulando o silogismo para ratificar os conteúdos, que é um fator importante para a organização e estrutura do conhecimento lógicomatemático. Logo, o professor pode representar problemáticas em que os alunos tenham que utilizar o envolvimento do corpo, como por exemplo, fazer grandes medições através do tamanho do passo, dessa maneira criando analogias para explanações, da mesma forma usar 
as habilidades de pensamento para solucionar tais atividades, sobretudo, além de estimular o pensamento lógico-matemático também atribuir valor aos alunos cinestésicos.

\subsection{Inteligência Cinestésico}

Nessa inteligência o professor pode criar ou construir materiais concretos em que ocorra a divisão da turma em equipes de acordo com a quantidade de alunos, posteriormente apresentado aos alunos um breve fator histórico do surgimento do conteúdo, como originouse, logo após, a explicação oral sobre o jogo, como foi elaborado, quais matérias utilizados, suas respectivas regras e o seu desenvolvimento, conjuntamente da exposição cinestésica, ou seja, o jogo será entregue no início da aula, pois sabemos que nem todos os objetos podem ser percebidos diretamente pelo visão e audição, alguns conceitos tem melhor entendimento por explicações orais juntamente com o tato. Em seguida expor uma problemática, para resolverem após o jogo. Voltada para os aspectos relacionados com a inclusão de todos os alunos na vivência das atividades e, ainda, com a experimentação de todas as funções existentes dentro do material proposto.

O professor também pode usar materiais práticos para comparar as informações obtidas para as diferentes formas de resolução, ou seja, além dos grupos compartilharem suas resoluções com os outros, realizando uma troca de conhecimento onde poderão discutir e fazer perguntas, estimulando dessa forma os estilos de aprendizagem. E a partir dos resultados encontrados pelos estudantes através do material, a formalização do conteúdo e alguns conceitos observados pelos estudantes apresentando as devidas definições matemáticas.

\subsection{Inteligência Interpessoal}

Para a inteligência interpessoal, se faz necessário o trabalho com os alunos, através de atividades que envolvam o diálogo e a troca de ideias sobre questões relacionadas a matemática. Consideramos importante ainda, que o aluno faça uso intencional das suas competências sociais para a aprendizagem.

A interação do grupo de classe deve assumir a condição de uma investigação, onde a cada reflexão sobre a ação realizadas buscam-se parâmetros para a reformulação das ações em devir. Nesse grupo que interage eu incluo o professor em seu papel intencional de ensinar: proponho a situação problema, fazendo as conclusões expressas pela classe e relacionando a linguagem emergente do grupo com a convencional da matemática (CARVALHO, 2011, p.103). 
Mediante este pensamento o professor deve propor atividades que auxiliem na interação dos alunos, a condução de grupos para que, planejem os procedimentos e realizem debates sobre textos que contenham algumas definições matemáticas, alguns exemplos, que podem estar corretos ou não e dessa forma propor para os alunos construírem modelos que unifique as concepções múltiplas.

Através do processo interpessoal a divisão dos alunos em grupos, promove debates e discussões que podem ser benéficas para a interação e troca de ideias entre os alunos, a fim de garantir que os alunos absorvam o máximo de conhecimento e habilidades, conduzindo-o a prática de dar e receber ajuda, questionamentos, modificações e aprimoramentos, "buscando através do aprendizado colaborativo estimular a compreensão do conteúdo" (ABREU, 2002, p.20), para que estejam sempre aptos a enfrentar e solucionar diferentes tipos de problemas em qualquer conjuntura, além disso, o professor tem que analisar os estilos de aprendizagem dos alunos e questionar-se sobre como irá atrair a atenção deles e despertar interesse principalmente para a matemática.

\subsection{Inteligência Visual- Espacial}

O desenvolvimento de métodos didáticos para estimular a inteligência visual-espacial, vem a ser considerável para o desenvolvimento das competências dessas habilidades, embora esteja relacionada diretamente com a matemática alguns alunos ainda sentem a dificuldade de associa-las com outros conteúdos, o despertar dessa inteligência pode ocorrer em vários momentos, como no estudo de geometria, funções e estatística, para isso existem alguns softwares educacionais, capazes de construir tabelas, gráficos, figuras geométricas, que podem ser trabalhados para representar um direcionamento na metodologia de suas aplicações, buscando absorver melhor as qualidades que estes softwares poderão oferecer, além disso podemos perceber que os alunos visuais têm maior facilidade com esse trabalho, então cabe ao professor estimular os demais tipos de estilos, segundo Amaral e Barros:

\footnotetext{
A teoria dos estilos de aprendizagem contribui muito para construção do processo de ensino e aprendizagem na perspectiva das tecnologias, porque considera as diferenças individuais e é flexível, o que permite estruturar as especificidades voltadas as tecnologias (2007, p.32).
}

A utilização do computador influencia bastante para os cinestésicos pois fazem o manuseio deste objeto para o processo de construção, por conseguinte para os alunos auditivos o professor deve oportunizar que eles expliquem a apresentação do que foi feito no 


\section{Res., Soc. Dev. 2019; 8(12):e198121670 \\ ISSN 2525-3409 | DOI: http://dx.doi.org/10.33448/rsd-v8i12.1670}

software, "buscando através do computador fazer o aluno visualizar aquilo que está sendo feito" (ABREU,2002,p.20).

\subsection{Inteligência Musical}

Para essa inteligência é competência do educador possibilita a evolução e interação entre o estudante e mundo externo, utilizando as atividades com teor pedagógico na formação da sua personalidade. A utilização da música torna-se importante para aprimorar a aprendizagem matemática. Santos e Alves diz que, "toda inteligência é estimulável e a competência musical é uma habilidade que nos permite apreciar, reproduzir e ter sensibilidade aos sons, aos ritmos e aos estímulos que nos possibilitam desenvolver essa capacidade" (2015, p. 2). Nesse sentido cabe ao professor observar e desenvolver essas habilidades a favor da matemática, Antunes também ressalta que:

\footnotetext{
Não acreditamos que existam professores "prontos" para desenvolver estímulos das inteligências e nem damos maior importância ao eventual talento para essa missão. Preferimos professores críticos e reflexivos que analisem elementos básicos essenciais a essa ação estimuladora e se acreditem em "pessoas em formação", que desenvolvam sua formação como uma conquista lenta, persistente e progressiva (ANTUNES, 2008. p.109).
}

Aprender através da música pode torna-se algo relevante para a aprendizagem matemática, não associando a uma prática decorativa, mas sim prazerosa, pois através dessa inteligência pode-se trabalhar com todos os estilos de aprendizagem, a leitura e composição de uma música estimula os visuais, já os alunos auditivos impulsionam seus ouvidos para identificar os padrões rítmicos, assim podendo relacionar a canção com os conteúdos matemáticos, dessa forma o professor poderá explicá-los. Para os cinestésicos tem-se o uso do instrumento para demonstrar alguns conteúdos, como por exemplo, o tambor que representa o cilindro para explicar os sólidos geométricos, assim a música sendo bem utilizada pode melhor a aprendizagem.

\subsection{Inteligência Intrapessoal}

A inteligência intrapessoal consiste em motivar os alunos a compreenderem os demais pensamentos, para que sintam se capazes de estudar determinado assuntos com nenhum direcionamento ou pelo menos um pouco para tentar chegar o mais próximo da solução. Para o ensino da Matemática esse processo é visto como uma estratégia que produz um 


\section{Res., Soc. Dev. 2019; 8(12):e198121670 \\ ISSN 2525-3409 | DOI: http://dx.doi.org/10.33448/rsd-v8i12.1670}

determinado sentido prático que causa significado ao autoconhecimento, fazendo com que o aluno aplique seus conhecimentos matemáticos já adquiridos, desenvolvendo a capacidade de superintender as informações em sua volta, dessa forma utilizando a aprendizagem autodirigida, essa inteligência tem maior influência nos alunos auditivos, pois as aulas na qual ocorre debates em grupos os ajuda a estabelecer sua linha de pensamento possibilitando o desenvolvimento dos conceitos matemáticos.

O saber matemático não pode continuar sendo privilégio de poucos alunos, tidos como mais inteligentes, cujo temperamento é mais dócil e, por isso, conseguem submeter-se ao "fazerem tarefas escolares" sem se preocuparem com o significado das mesmas no que se refere ao seu processo de construção do conhecimento (CARVALHO, 2011, p. 103).

Através desse pensamento, o professor deve estabelecer para os alunos, conhecimentos sobre a maneira de solucionar problemas, os alunos cinestésicos por exemplo, ao receberem ajuda de outra colega e seguindo as instruções do mesmo, irá prepará-lo para solucionar quaisquer conflitos, eliminando suas deficiências intelectuais e trazendo o autoconhecimento para uma existência crítica e reflexiva. Para os visuais o professor poderia trabalhar o uso de portfólio fazendo com que o aluno escreva sobre conteúdos na qual sente dificuldade, como Abreu sugere:

\footnotetext{
Uma outra sugestão para trabalhos futuros seria o uso de um "processofolio". Desde o início dos trabalhos, os alunos montarem um portfólio para documentarem para eles mesmos, o pedregoso caminho que eles trilharam e pudessem assim verificar o quanto eles se desenvolveram dentro dos conteúdos trabalhados. Isto traria aos alunos um incentivo a mais para continuar nesse difícil caminho que é o caminho do aprendizado (2002, p.98).
}

A percepção consiste em fazer com que o aluno construa e procure um objetivo para seu o seu estudo, a finalidade na qual ele pretende estudar e o que está sendo um desafio para sua compreensão, para que depois possa fazer uma avaliação do próprio trabalho.

\subsection{Inteligência Naturalista}

Quando se refere a inteligência naturalista, salienta-se a importância na qual deve-se ter sobre ela, refletindo uma análise difícil da realidade vivenciada na sala de aula, levando em consideração o saber ambiental, mas não apenas ele, como também as suas divergências e seus contextos, onde se tem uma colocação fundamental em toda a sua análise. Entretanto é dever do educando desenvolver intervenções pedagógicas para essas competências, pois o próprio não deve ser distinguido como um produto, mas sim como forma de intercalar na educação do aluno em relação com a natureza. 
Res., Soc. Dev. 2019; 8(12):e198121670

ISSN 2525-3409 | DOI: http://dx.doi.org/10.33448/rsd-v8i12.1670

[...] com um potencial biopsicológico para processar informações que pode ser ativado num cenário cultural para solucionar problemas ou criar produtos que sejam valorizados numa cultura. (...) as inteligências não são objetos que podem ser vistos nem contados. Elas são potenciais-neurais presumivelmente- que poderão ser ou não ativadas, dependendo dos valores de uma cultura especifica, das oportunidades disponíveis nessa cultura e das decisões pessoais tomadas por indivíduos e/ou suas famílias, seus professores e outros (Gardner, 2000, p.47).

Mediante este pensamento, sugere-se aos professores trabalhar de maneira sucinta esta inteligência, visto que há diversas formas de explorá-la como por exemplo, a realização de uma aula de campo em que os alunos iriam observar, coletar e categorizar os dados obtidos, depois realizar uns registros dessas observações, e depois explicar como uma espécie de planta se assemelha a outra, ou seja, isto envolverá todos os estilos de aprendizado.

Se, de um lado, o estudo da evolução humana mostra que as inteligências naturalista, cinestésica-corporal e visuo-espacial são, na sua origem, estritamente relacionadas entre si, de outro lado, no desenvolvimento cognitivo do ser humano, essas mesmas inteligências também parecem manter uma estreita relação (NICOLLIER, VELASCO, 2008, p. 31).

Ao exercer essas relações, é indubitável que o professor de matemática deve analisar práticas significativas de ação em sala de aula que aumentem a capacidade de matematizar conjunturas reais, apresentando atividades conectadas com diversas áreas do conhecimento que estão envolvidas no meio naturalista, implementando relações entre os problemas ambientais.

\section{Conclusão}

Compreender as funções do cérebro para melhorar suas práticas e também lidar com as dificuldades e potencialidades dos alunos e, efetivamente, o bom resultado do aluno está na boa realização das metodologias aplicadas em sala de aula, para isso é necessário que o professor busque uma formação continuada com assistência da neurociência, proporcionando aos alunos uma aprendizagem matemática satisfatória e assim, melhorar o desempenho e as atitudes dos alunos. Através do presente estudo podemos concluir que existe uma relação efetiva entre os estilos de aprendizagem e as inteligências múltiplas.

Buscando suporte alternativo ao ensino da Matemática, a neuroeducação nos mostra que nenhum aluno é incapaz de aprender, basta o professor de matemática inovar e trazer novas estratégias de ensino capazes de abranger todas as competências e habilidades, o presente estudo nos fornece várias formas de estimulá-las. Nesse sentido, é importante perceber que os alunos trazem competências múltiplas, assim as análises limitaram-se em compreender como estas organizam seus conhecimentos e desenvolvem suas aprendizagens, é 
o começo para a construção do trabalho matemático pedagógico do professor. Da mesma forma, se o professor de matemática descobrir como os alunos aprendem, saberá como ensinar e desenvolverá a capacidade do aluno de alcançar seu potencial, complementando também sua capacidade de aprendizagem.

Entretanto, para que venha ocorrer todo esse processo evolutivo no ensino da Matemática, muitos professores deverão mudar suas concepções pejorativas de ensino, deixar a visão tradicionalista e entender que o novo também é válido, que novos conhecimentos acerca do cérebro são relevantes, sobretudo, o presente trabalho contribui para essa compreensão, na qual é necessário o entendimento do conhecimento cientifico, para a obtenção da aprendizagem, por conseguinte do sucesso profissional.

Contudo, o estudo do cérebro para as aulas de matemática trará muitas vantagens tanto para os professores, que facilitará o desempenho dos alunos, quanto para os alunos que poderão interagir e aprender de formas diferentes, visto que, aprender, modifica o cérebro e isso é de suma importância. Os alunos criando e desenvolvendo um pensamento e um raciocínio matemático onde aumentará o nível de educação e de aproveitamentos da vida estudantil dos alunos.

Em relação do professor saber os diferentes estilos de aprendizagem da turma e em especial de cada um individualmente certamente fará com que o professor planeje e aplique um conteúdo que seja de compreensão de todos, além de sugerir atividades que consigam resolver com seus conhecimentos já adquiridos, pois quando o aluno acerta, mais aumenta seu interesse pelo saber e consequentemente uma melhor compreensão nos conteúdos posteriores. Tornando-se evidente, portanto, que a aula com caráter inclusivo, com o professor buscando compreender quais são as habilidades e observando o estilo de aprendizagem e as inteligências múltiplas de cada aluno, ele irá conseguir êxito e resultados satisfatórios dos alunos nas atividades escolares.

Em investigações futuras, apresentamos como sugestão essas e outras atividades que estimule as inteligências múltiplas dos alunos por meio dos estilos de aprendizagem. A prática comprovaria a real validade do estudo do cérebro para as aulas de matemática.

\section{Referências}

Abreu, K. Uma Aplicação Das Inteligências Múltiplas No Aprendizado De Matemática:

Representação Gráfica De Funções De 1o. E 2o. Graus, 2002. Disponível Em: 
Https://Repositorio.Ufsc.Br/Bitstream/Handle/123456789/83280/190836.Pdf?Sequence=1 . Acesso Em: 22 Ago. 2018.

Amaral, S.F; Barros, D.M.V. Estilos De Aprendizagem No Contexto Educativo De Uso Das Tecnologias Digitais Interativas, 2007. Disponível Em:

Https://Edisciplinas.Usp.Br/Pluginfile.Php/813099/Mod_Resource/Content/1/Leitura\%20estil os\%20de\%20aprendizagem.Pdf . Acesso Em: 21 Ago. 2018.

Antunes, C. As Inteligências Múltiplas E Seus Estímulos. Campinas/Sp: Papirus (Coleção Papirus Educação)14 ${ }^{\text {a }}$ Ed. 2008.

Armstrong, T. J.; Veronese, M. A. V. Inteligências Múltiplas Na Sala De Aula. Artmed, 2001.

Brasil. Mec. Ministério Da Educação E Do Desporto. Parâmetros Curriculares Nacionais. Brasil, 1997.

Calazans, F. Propaganda Subliminar Multimídia $7^{\text {a }}$ Ed, Summus Ed., São Paulo, 2006.

Carvalho, F. H. De Neurociências E Educação: Uma Articulação Necessária Na Formação Docente. Trabalho, Educação E Saúde. Rio De Janeiro, V. 8 N. 3, Nov.2010/Fev.2011.

Conseza, R. M.; Guerra, L. B. Neurociência E Educação: Como O Cérebro Aprende. Porto Alegre-Rs: Artmed, 2011.

Dos Santos, C. P; Sousa, K. Q. A Neuroeducação E Suas Contribuições Às Práticas Pedagógicas Contemporâneas. Encontro Internacional De Formação De Professores E Fórum Permanente De Inovação Educacional, V. 9, N. 1, 2016

Duarte, M. J. P; Varo, C. V. Lenguaje Y Cerebro: Conexiones Entre Neurolingüística Y Psicolingüística. In: Actas Del Primer Congreso Nacional De Lingüística Clínica. 2006. P. 107-119. 
Espinosa. T. N. The Scientifically Substantiated Art Of Teaching: A Study In The Development Of Standards In The New Academic Field Of Neuroeducation (Mind, Brain, And Education Science). Tese De Doutorado, Programa De Pós-Graduação Em Educação, Capella University, Mineápolis, Minesota. 2008.

Freire, P. Pedagogia Do Oprimido. 41. Ed. Rio De Janeiro: Paz E Terra, 2005.

Gazzaniga, M. S.; Heatherton, T.F. Ciência Psicológica: Mente, Cérebro E Comportamento. Trad. De Maria Adriana Veríssimo Veronese. Consultoria E Supervisão: Vitor Geraldi Haase. $1^{\mathrm{a}}$. Ed. Porto Alegre: Artmed, 2005.

Gardner, H. (1995). Inteligências Múltiplas: A Teoria Na Prática. Porto Alegre: Artes Médicas.

Gardner, H. (2002). Estruturas Da Mente: A Teoria Das Múltiplas Inteligências. Porto Alegre: Artes Médicas.

Gil, A. C. Como Classificar As Pesquisas. Como Elaborar Projetos De Pesquisa, V. 4, P. 44-45, 2002.

Guerra. L. B. Como As Neurociências Contribuem Para Educação Escolar? Fgr, Revista, Ano 04. N5 De Outubro De 2010.

Guerra, L. B. O Diálogo Entre A Neurociência E A Educação: Da Euforia Aos Desafios E Possibilidades. Revista Interlocução, V.4, N.4, P.3-12, Publicação Semestral, Junho/2011.

Hardiman, M; Denckla, M. B. The Science Of Education: Informing Teaching And Learning Through The Brain Sciences. Cerebrum, V. 11, N. 12, P. 1-9, 2009.

Kahneman, Daniel. Rápido E Devagar: Duas Formas De Pensar. Objetiva, 2012.

Maclean, P. D. The Triune Brain In Evolution Role In Paleocerebral Functions Plenum Publishing Corporation, New York, 1989. 
Nicollier, V.; Velasco, F. G. C. A Inteligência Naturalista: Um Novo Caminho Para A Educação Ambiental. Revista Eletrônica Do Prodema, 2008, 2.1: 19-44.

Oliveira, Gilberto Gonçalves De. Neurociência E Os Processos Educativos: Um Saber Necessário Na Formação De Professores. Uberaba: Universidade De Uberaba, 2011.

(Dissertação - Mestrado Em Educação).

Relvas, M. P. Neurociência Na Prática Pedagógica. Rio De Janeiro: Wak, 2012.

Sadovsky, P. Falta Fundamentação Didática No Ensino Da Matemática. Nova Escola. São Paulo, Ed. Abril, Jan. /Fev. 2007.

Saldanha, C. C., Zamproni E. C. B. \& Batista, M. L.A. Semana Pedagógica-Estilos De Aprendizagem. Paraná, 2016. Disponível Em:

Http://Www.Gestaoescolar.Diaadia.Pr.Gov.Br/Arquivos/File/Sem_Pedagogica/Julho_2016/D ee_Anexo1.Pdf. Acesso Em: 26 De Jul. De 2018.

Santos, A. M; Alves, T. S. A Inteligência Musical E Suas Implicações Na Formação Do Leitor. Encontro Internacional De Formação De Professores E Fórum Permanente De Inovação Educacional, 2015. Disponível Em:

Https://Eventos.Set.Edu.Br/Index.Php/Enfope/Article/Viewfile/1377/292 . Acesso Em 25 Ago. 2018.

Silver, L. Dificuldades De Aprendizagem. [S.I]: Adhd, Eeuu, Ciba-Geigy Corporation, 1994.

Vygotsky, L. S. Interação Entre Aprendizado E Desenvolvimento. In: A Formação Social Da Mente. 4. Ed. São Paulo: Martins Fontes, 1991.

Vygotsky, L. S. Aprendizagem E Desenvolvimento Na Idade Escolar. In: Linguagem, Desenvolvimento E Aprendizagem. Vigostky, L. Luria, A. Leontiev, A.N. 11 a . Edição. São Paulo: Ícone, 2010, P. 103-116.

Vigotsky, L. S. Imaginação E Criação Na Infância. São Paulo: Ática, P. 16, 2009. 
Porcentagem de contribuição de cada autor no manuscrito

Francisco Geovane da Silva Araújo - 50\%

Daniel Brandão Menezes - 40\%

Karoline de Sousa Bezerra - 10\% 